\title{
Overexpression of secretory phospholipase A2-IIa supports cancer stem cell phenotype via HER/ERBB-elicited signaling in lung and prostate cancer cells
}

\author{
SHAN LU and ZHONGYUN DONG \\ Department of Medicine, University of Cincinnati College of Medicine, Cincinnati, OH 45267, USA
}

Received February 24, 2017; Accepted April 10, 2017

DOI: 10.3892/ijo.2017.3964

\begin{abstract}
Resistance to conventional chemotherapies remains a significant clinical challenge in treatment of cancer. The cancer stem cells (CSCs) have properties necessary for tumor initiation, resistance to therapy, and progression. HER/ERBB-elicited signaling supports CSC properties. Our previous studies revealed that secretory phospholipase A2 group IIa (sPLA2-IIa) is overexpressed in both prostate and lung cancer cells, leading to an aberrant high level in the interstitial fluid, i.e., tumor microenvironment and blood. HER/ERBB-PI3K-Akt-NF- $\kappa$ B signaling stimulates sPLA2-IIa overexpression, and in turn, sPLA2-IIa activates EGFR family receptors and HER/ERBB-elicited signaling and stimulates sPLA2-IIa overexpression in a positive feedback manner. The present study determined the molecular mechanisms of sPLA2-IIa in stimulating HER/ERBB-elicited signaling and supporting CSC properties. We found that SPLA2-IIa binds both EGFR and HER3 demonstrated by co-immunoprecipitation experiments and also indirectly interacts with HER2, suggesting that sPLA2-IIa functions as a ligand for both EGFR and HER3. Furthermore, both side population CSCs from non-small cell lung cancer (NSCLC) A549 and H1975 cells and ALDH1-high CSCs from castration-resistant prostate cancer (CRPC) 22Rv1 cells overexpress sPLA2-IIa and produce tumors when inoculated into subcutis of nude mice. Given an aberrant high level of sPLA2-IIa in the tumor microenvironment that should be much higher than that in the blood, our findings support the notion that SPLA2-IIa functions as a ligand for EGFR family receptors and supports CSC properties via HER/ERBB-elicited signaling, which may contribute to resistance to therapy and cancer progression.
\end{abstract}

Correspondence to: Dr Zhongyun Dong, Division of HematologyOncology, Department of Medicine, Vontz Center for Molecular Studies, University of Cincinnati College of Medicine, Rm 1308, 3125 Eden Ave., Cincinnati, OH 45267, USA

E-mail: dongzu@ucmail.uc.edu

Key words: cancer stem cells, HER/HER2-elicited signaling, secretory phospholipase A2-IIa, ligand, EGFR family receptors, tumor microenvironment

\section{Introduction}

The cancer stem cells (CSCs) are a rare population of tumor cells and enable them to simultaneously self-perpetuate with a consistently maintained CSC subpopulation and to generate differentiated progeny via asymmetrical cell division, giving rise to heterogenic tumors (1-3). CSCs are relatively quiescent and have the properties necessary for tumor initiation, resistance to therapy, and progression (4-7). The CSC population expands during periods of stress, such as radiation $(8,9)$, chemotherapy (5), and castration (10), which are likely the initiating cells of chemoresistant cancer relapses and metastases. Based on CSC markers, a number of CSC populations have been identified. For instance, the side population (SP) cells, which express high levels of ABCG2 and ABCB1 multidrug efflux pumps that may contribute to chemoresistance, possess the stem cell-like properties $(2,3,11)$. The aldehyde dehydrogenases (ALDH) are cytosolic isoenzymes responsible for oxidizing intracellular aldehydes. The ALDH1-high cell subpopulations show distinct stem-like characteristics and are highly resistant to chemotherapeutic agents commonly used as first-line therapy, such as cisplatin and docetaxel $(2,3)$. The current anticancer therapies fail to destroy, but tend to favor the selection and expansion of resistant CSCs in tumors, resulting in poor responses and outcomes. The elimination of CSCs is of utmost importance at the time of therapeutic intervention in order to prevent CSC expansion and subsequent tumor recurrence, relapse, and metastasis.

Secretory phospholipase A2 group IIa (sPLA2-IIa) is distributed in trace amounts in a variety of normal mammalian tissues, but found at high levels in various inflamed tissues and some cancers. sPLA2-IIa, a NF- $\mathrm{kB}$ target gene $(12,13)$, has traditionally been associated with their enzymatic activity and participates in biosynthesis of potent biologically active lipid mediators, particularly arachidonic acid-derived eicosanoids, which promote inflammation, angiogenesis, and tumorigenesis $(14,15)$. Independent of its enzymatic activity, sPLA2-IIa can also serve as a ligand for cell membrane receptors and stimulate integrin activation, COX-2 expression, and secretion of cytokines (16-18). sPLA2-IIa binds to integrin av $\beta 3$ at $K_{D}$ of $0.2 \mathrm{mM}$, and induces cell proliferation (16). sPLA2-IIa also weakly interacts with M-type receptor in human cells and induces pro-inflammatory signaling $(15,19,20)$. 
sPLA2-IIa is associated with the pathology of several types of malignancies, including cancers of the colon, breast, stomach, esophagus, ovary, lung, and prostate (21,22). sPLA2-IIa is overexpressed in almost all human prostate cancer tissues and elevated levels are associated with advanced tumor grades (13,23-26). sPLA2-IIa remains elevated in androgen-independent prostate cancers (27) and is significantly increased in metastatic lesions (28). We are the first to demonstrate that cancer cells overexpress and secrete sPLA2-IIa into the interstitial fluids, i.e., tumor microenvironment and blood, in patients with both prostate and lung cancers $(13,29,30)$. High levels of plasma sPLA2-IIa are associated with poor prognosis, advanced cancer stage, and short cancer survival. We confirmed that tumors secret SPLA2-IIa into the circulation to a detectable level in the mouse model of human cancer (29). The most recent report by others supports our finding in that high levels of plasma sPLA2-IIa are associated with poor prognosis of cancers (31). More importantly, we revealed that elevated HER/ERBB-PI3K-Akt-NF- $\mathrm{KB}$ signaling induces sPLA2-IIa overexpression and secretion in both lung and prostate cancer cells; in turn, sPLA2-IIa stimulates its overexpression via HER/ERBB-elicited signaling in the positive feedback regulation manner $(26,32)$. sPLA2-IIa induces phosphorylation of HER 2 and HER3 in a dose-dependent manner in NSCSC A549 and H1975 cells (32). However, the underlying molecular mechanisms of sPLA2-IIa at an aberrant high level in the tumor microenvironment in stimulating cancer progression and metastasis remains to be elucidated.

The HER/ERBB-elicited signaling is essential for cell growth and survival. Recent studies further demonstrate that this signaling pathway is of critical importance in supporting CSC properties (33-35). We determined a role of sPLA2-IIa in CSCs and revealed that sPLA2-IIa is overexpressed in both side population (SP) CSCs from NSCSC cells and ALDH1-high CSCs from CRPC cells. Furthermore, sPLA2-IIa directly interacts with and activates EGFR family receptors, suggesting that SPLA2-IIa is a ligand for both EGFR and HER3. These findings, together with our previous data $(13,29,30,32)$, support the notion that high levels of sPLA2-IIa in the tumor microenvironment support CSC phenotype via HER/ERBB-elicited signaling, and sPLA2-IIa is a novel therapeutic target against cancer and CSCs.

\section{Materials and methods}

Reagents. RPMI-1640 medium was purchased from Invitrogen (Gaithersburg, MD, USA). Fetal bovine serum (FBS) and charcoal/dextran-treated FBS were purchased from Hyclone Laboratories (Logan, UT, USA). sPLA2-IIa antibodies were obtained from Life Span BioSciences (Seattle, WA, USA) and Cayman Chemical (Ann Arbor, MI, USA). Recombinant human sPLA2-IIa was obtained from BioVendor (Candler, NC, USA). EGFR, HER2, and HER3 antibodies were from Cell Signaling Technology (Danvers, MA, USA) and Santa Cruz Biotechnology (Santa Cruz, CA, USA). RT-PCR primers were customly synthesized by Genscript (Piscataway, NJ, USA). Plasmid sPLA2-IIa(-800)-Luc was constructed as we described previously (13).

Cell culture. The human prostate adenocarcinoma cell lines LNCaP and 22Rv1, and lung cancer adenocarcinoma H1975 were obtained from ATCC (Rockville, MD, USA) and maintained in RPMI-1640 medium supplemented with 10\% FBS (complete medium) at $37^{\circ} \mathrm{C}$ in $5 \% \mathrm{CO}_{2}$. LNCaP-AI cells were generated by us previously (36) and maintained in RPMI-1640 medium supplemented with $10 \%$ charcoal/dextran-treated FBS (stripped medium). Lung cancer adenocarcinoma A549 cells were obtained from ATCC and maintained in MEM medium supplemented with 5\% FBS (complete medium) at $37^{\circ} \mathrm{C}$ in $5 \% \mathrm{CO}_{2}$.

$3 D$ cell culture. A 96-well plate was coated with $100 \mu 1 /$ well of medium containing $0.9 \%$ agarose. SP CSCs and non-SP control cells in medium with $10 \%$ FBS on ice were mixed with a same volume of cold $\left(4^{\circ} \mathrm{C}\right)$ medium containing $10 \% \mathrm{FBS}$ and $10 \%$ growth factor-reduced Matrigel matrix (BD Biosciences, Bedford, MA, USA) and seeded into the agarose plate at $100 \mu \mathrm{l} /$ well. The cells were cultured at $37^{\circ} \mathrm{C}$ for 14 days.

CSC sorting. The ALDH1-high CSCs from 22Rv1 cells was isolated using the Aldefluor assay kit (StemCell Technologies, Vancouver, Canada) and BD FACSAria II cell sorters. ALDH1 cleaves boron-dipyrromethene-aminoacetaldehyde (BAAA) to release fluorescent dye, which can be blocked by diethylaminobenzaldehyde (DEAB). After gating with DEAB control, the fluorescent cells were sorted out as ALDH1-high CSCs.

SP CSCs were isolated as previously described (37). Briefly, A549 and H1975 cells were resuspended at $1 \times 10^{6} / \mathrm{ml}$ in prewarmed DMEM with $2 \%$ FCS and $10 \mathrm{mmol} / 1$ HEPES buffer. Hoechst 33342 dye was added at a final concentration of $5 \mu \mathrm{g} / \mathrm{ml}$ in the absence or presence of reserpine $(50 \mu \mathrm{mol} / \mathrm{l}$; Sigma) and the cells were incubated at $37^{\circ} \mathrm{C}$ for 90 min with intermittent shaking. At the end of the incubation, the cells were washed with ice-cold HBSS with $2 \% \mathrm{FCS}$ and $10 \mathrm{mmol} / 1$ HEPES, centrifuged down at $4^{\circ} \mathrm{C}$, and resuspended in ice-cold HBSS containing 2\% FCS and $10 \mathrm{mmol} / \mathrm{l}$ HEPES. Propidium iodide at a final concentration of $2 \mu \mathrm{g} / \mathrm{ml}$ was added to gate viable cells. Gated by control cells treated with reserpine that blocks Hoechst 33342 transporter, SP CSCs were sorted using BD FACSAria II cell sorters. SP CSCs were defined as the missing region in the presence of reserpine.

Tumorigenesis in mice. One thousand of CSCs or control cells in $50 \mu$ l PBS were mixed with $50 \mu$ l of cold Matrigel (Thermo Fisher Scientific) and inoculated subcutaneously into nude mice. Tumor incidence and sizes were measured using calipers and recorded twice a week. The mice were maintained in a facility approved by the American Association for Accreditation of Laboratory Animal Care (AAALAC) and in accordance with current regulations and standards of the U.S. Department of Agriculture, U.S. Department of Health and Human Services, and NIH. The animal studies were approved by the Institutional Animal Care and Use Committee (IACUC) and executed according to IACUC guidelines.

$R T$-PCR. RNAs from both CSCs and control cells were isolated using RNeasy Plus Universal Mini kit (Qiagen, Germany). RNA samples were then treated with DNase using DNA-free ${ }^{\mathrm{TM}}$ kit (Thermo Fisher Scientific) and subjected to reverse transcription reactions using High Capacity cDNA Reverse Transcription kits (Applied Biosystems, Thermo Fisher Scientific). Real-time 
A

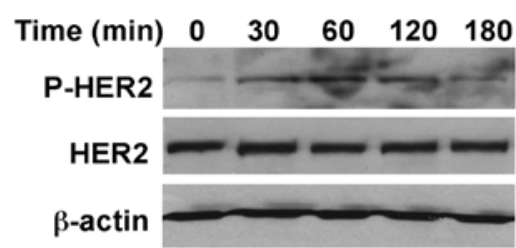

C

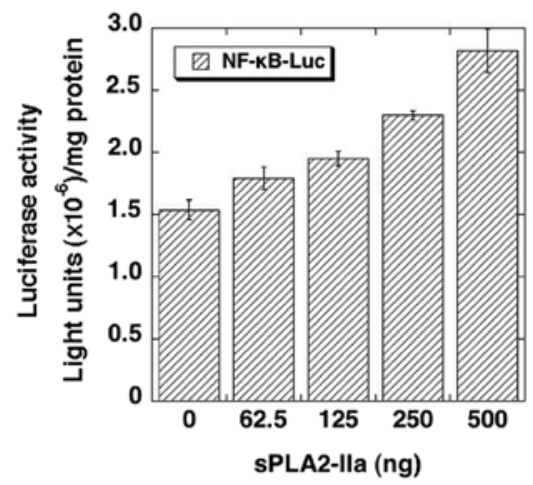

E

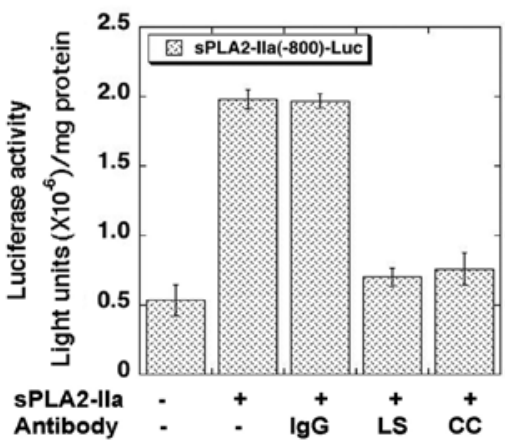

B

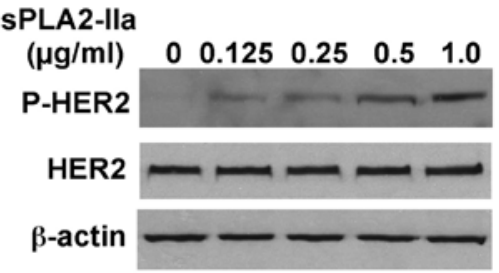

D

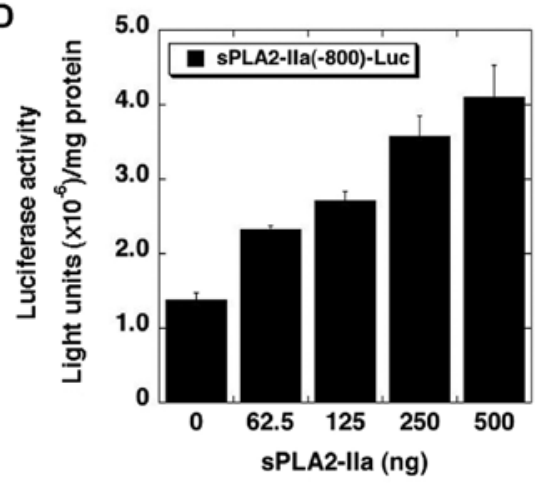

Figure. 1. sPLA2-IIa enhances HER/ERBB-elicited signaling. LNCaP-AI cells were treated with $0.5 \mathrm{mg} / \mathrm{ml}$ of recombinant human sPLA2-IIa for 30-180 min (A) or various concentration of sPLA2-Ia for $2 \mathrm{~h}$ (B). The cell extracts were then prepared and subjected to western blotting for HER2 and $\mathrm{P}$-HER2. LNCaP cells in a 12-well plate were transfected with NF- $\kappa \mathrm{B}-\mathrm{Luc}(\mathrm{C})$ or sPLA2-IIa(-800)-Luc (D and E) reporter overnight, then treated with recombinant human sPLA2-IIa (C and D) or $0.5 \mathrm{mg} / \mathrm{ml}$ recombinant human sPLA2-IIa without or with $0.5 \mathrm{mg} / \mathrm{ml} \mathrm{IgG} \mathrm{or} \mathrm{anti-human} \mathrm{sPLA2-IIa} \mathrm{anti-}$ bodies from Life Span BioSciences (LS) or Cayman Chemical (CC) (E) in the medium containing $10 \%$ FBS for $24 \mathrm{~h}$, followed by luciferase assay.

probed with first antibody in PBS containing $0.01 \%$ Tween-20 (PBST) and $1 \%$ fat-free milk. The membranes were then washed four times in PBS and incubated with IRDye $800 \mathrm{CW}$ secondary antibody (LI-COR Biosciences, Lincoln, NE, USA) in PBST containing $1 \%$ fat-free milk for $30 \mathrm{~min}$. After washing four times in PBS, the membranes were visualized using Odyssey imaging system (LI-COR).

Reporter assay. Cells (10\%/well) were seeded in 12-well tissue culture plates. The next day, Lipofectamine 3000 reagent was used for the transient transfection assay according to the protocol provided by Invitrogen/Life Technologies, Inc. The cells were then treated for $24 \mathrm{~h}$. Subsequently, the cell extracts were prepared and luciferase activity was assessed in a Berthold Detection system (Titertek-Berthold, Pforzheim, Germany) using a Luciferase assay kit (Promega, Madison, WI, USA) according to the manufacturer's instructions. For each assay, cell extract $(20 \mu \mathrm{l})$ was used and the reaction was started by injection of $50 \mu \mathrm{l}$ of luciferase substrate. Each reaction was measured for $10 \mathrm{sec}$ in the luminometer. Luciferase activity was defined as light units/mg protein.

\section{Results}

SPLA2-IIa stimulates HER/ERBB-elicited signaling in cancer cells. We reported previously that treatment of NSCLC A549 and H1975 cells with recombinant human sPLA2-IIa onto a $0.45-\mathrm{mm}$ nitrocellulose membrane (Bio-Rad). The membranes were blocked with $2 \%$ fat-free milk in PBS, and
Western blot analysis. Western blot analysis was performed as previously described (13). Briefly, aliquots of samples with the kit (Bio-Rad, Hercules, CA, USA buffer (final concentrations of $62.5 \mathrm{mM}$ Tris- $\mathrm{HCl}, \mathrm{pH} 6.8$, $2.3 \%$ SDS, $100 \mathrm{mM}$ dithiothreitol, and $0.005 \%$ bromophenol blue), boiled, fractionated in an SDS-PAGE, and transferred 


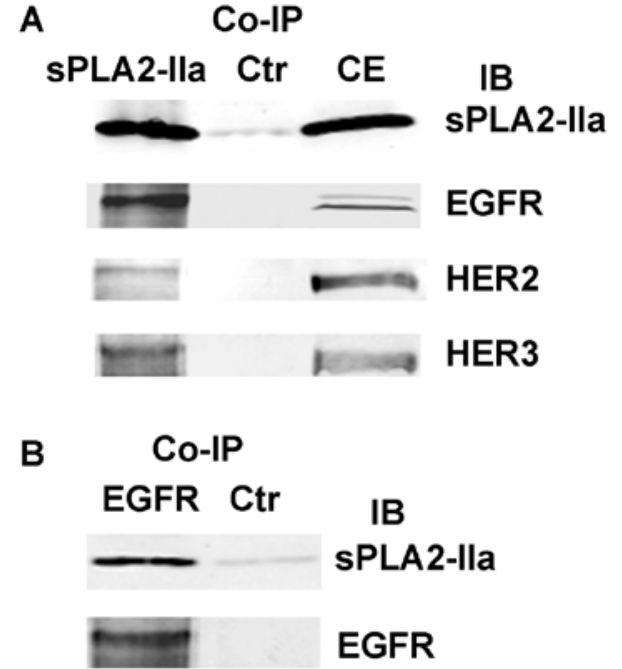

Figure 2. Determination of the interaction between sPLA2-IIa and EGFR family receptors by co-immunoprecipitation (co-IP) assay. Cell extract from LNCaP-AI cells were used for co-IP with either anti-sPLA2-IIa antibody (A) or anti-EGFR antibody (B). The samples without antibody were used as co-IP control (Ctr). Subsequently, the samples were fractionated by SDS-PAGE, followed by immunoblot (IB) analysis using antibodies to sPLA2-IIa, EGFR, HER2, or HER3, respectively. Cell extract (CE) from LNCaP-AI cells served as IB control.

induces phosphorylation of HER 2 and HER 3 within $2 \mathrm{~h}$ in a dose-dependent manner (32). The reporter assay revealed that sPLA2-IIa enhances the promoter activities of NF- $\mathrm{KB}$ and sPLA2-IIa genes in a dose-dependent manner in lung cancer cells. For validation, we determined the effects of sPLA2-IIa in prostate cancer cells. As shown in Fig. 1A and B, recombinant human sPLA2-IIa induces phosphorylation of HER2 within $2 \mathrm{~h}$ in a dose- and time-dependent manner in CRPC LNCaP-AI cells (36). sPLA2-IIa also enhances the promoter activities of NF-KB (Fig. 1C) and sPLA2-IIa (Fig. 1D) genes in a dose-dependent manner in the cells. The stimulatory effects of sPLA2-IIa on sPLA2-IIa promoter activity were abolished by antibodies against sPLA2-IIa (Fig. 1E). These data implicated that sPLA2-IIa enhances HER/ERBB-elicited signaling in prostate cancer cells.

sPLA2-IIa functions as a ligand for EGFR family receptors. A structural analysis we performed previously suggests that the sPLA2-IIa $\beta$ hairpin shares significant similarity with the EGF hairpin and could be displaced to provide additional contacts with EGFR, and protein docking computation shows that sPLA2-IIa directly interacts with the extracellular domain (ECD) of EGFR in such a way as to stabilize EGFR in its active conformation (32). For validation of the interactions of sPLA2-IIa with EGFR family receptors, co-immunoprecipitation (co-IP) was performed using cell extracts from LNCaP-AI cells. As shown in Fig. 2A, EGFR, HER2, and HER3 were detected in the co-IP complex pulled down by an antibody to sPLA2-IIa. Reciprocally, sPLA2-IIa was detected in the co-IP complexes pulled down by an antibody to EGFR (Fig. 2B). These data reveal that sPLA2-IIa activates EGFR family receptors and complexes with EGFR, HER2, and HER3, strongly suggesting that sPLA2-IIa is a novel ligand for EGFR and HER3 (32).
A Side population (SP)

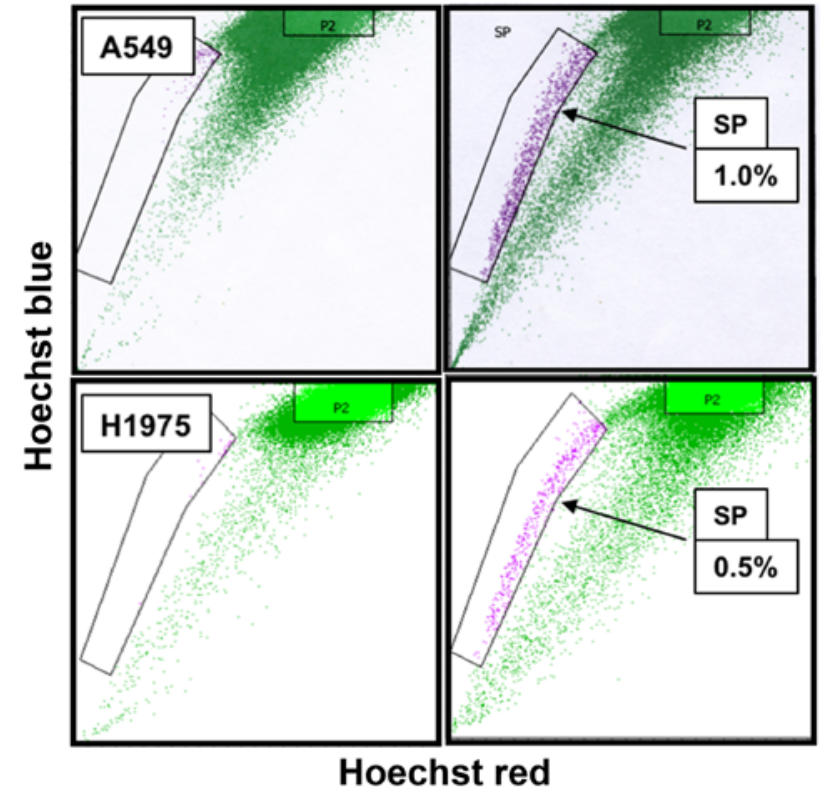

B ALDH1-high

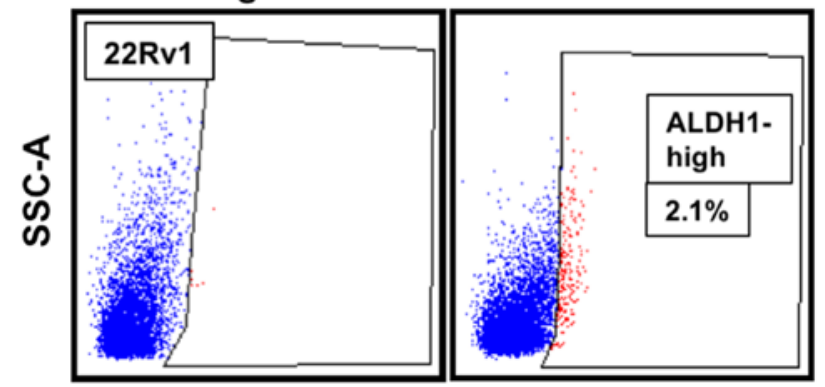

Alexa fluor 488-A

Figure 3. Isolation of CSCs. (A) SP CSCs from A549 and H1975 cells. The SP gate was defined as the missing region (in purple) in the presence of reserpine that blocks the activity of Hoechst 33342 transporter and sorted using BD FACSAria II cell sorters. The cells collected from $\mathrm{P} 2$ region (in green) were used as non-SP control. (B) ALDH1-high CSCs from 22RV1 cells. ALDH1-high cells (in red) were isolated using the ALDEFluor assay kit and BD FACSAria II cell sorters.

Overexpression of SPLA2-IIa in CSCS. SP CSCs express high levels of ABCG2 and/or ABCB1 multidrug efflux pump proteins and possess stem cell-like properties (37). We isolated SP CSCs from NSCLC cells using flow cytometry and Hoechst 33342 dye efflux assay (37) and found $\sim 1 \%$ of SP CSCs in A549 cells and 0.5\% of SP CSCs in H1975 cells (Fig. 3A). ALDH1 is a universal functional marker for CSCs (38-44) and is involved in cellular responses to oxidative stress (42) and drug resistance (41). Overexpression of ALDH1 correlates with poor prognosis in prostate cancer (38). ALDH1-based approach has been used to successfully isolate CSCs from many cell lines of diverse cancer types $(45,46)$, including CRPC 22Rv1 and PC-3 cells $(39,44)$. Consistent with data reported in the literature (44), we found $\sim 2.1 \%$ of ALDH1-high CSCs in 22Rv1 cells (Fig. 3B).

The real-time RT-PCR was performed to determine expression of CSC marker genes in the CSCs. As shown in (Tables I and II), the CSC markers, including ABCG2, ALDH1, CD133, CD44, CD56, Focx2, MDR1, Nanog, 
Table I. Primers used for RT-PCR.

\begin{tabular}{|c|c|c|}
\hline \multirow[t]{2}{*}{ ABCG2 } & Upper primer & 5'-AAACCTGGTCTCAACGCCATCC-3' \\
\hline & Lower primer & 5'-TGCCCATCACAACATCATCTTG-3' \\
\hline \multirow[t]{2}{*}{ ALDH1 } & Upper primer & 5'-CTTACCTGTCCTACTCACCGATTTG-3' \\
\hline & Lower primer & 5'-CCTTGTCAACATCСТCСТTATCTCC-3' \\
\hline \multirow[t]{2}{*}{ AR } & Upper primer & 5'-GTCTTCGGAAATGTTATGAAGCA-3' \\
\hline & Lower primer & 5'-ACGATCGAGTTCCTTGATGTAG-3' \\
\hline \multirow[t]{2}{*}{ CD133 } & Upper primer & 5'-TGAGACCCAAGACTCCCATAAAGC-3' \\
\hline & Lower primer & 5'-GGACACAGCATAGAATAATCCCTGC-3' \\
\hline \multirow[t]{2}{*}{ CD44 } & Upper primer & 5'-CGTGGAGAAAAATGGTCGCTAC-3' \\
\hline & Lower primer & 5'-TACTGGGAGGTGTTGGATGTGAGG-3' \\
\hline \multirow[t]{2}{*}{ CD56 } & Upper primer & 5'-CGGCATTTACAAGTGTGTGG-3' \\
\hline & Lower primer & 5'-GACATCTCGGCCTTTGTGTT-3' \\
\hline \multirow[t]{2}{*}{ Focx 2} & Upper primer & 5'-AGAATTACTACCGGGCTGCG-3' \\
\hline & Lower primer & 5'-TGAGCGCGATGTAGCTGTAG-3' \\
\hline \multirow[t]{2}{*}{ HER2 } & Upper primer & 5'-AATGGAGACCCGCTGAACAATAC-3' \\
\hline & Lower primer & 5'-CACAAAATCGTGTCCTGGTAGCAG-3' \\
\hline \multirow[t]{2}{*}{ HER3 } & Upper primer & 5'-TACGAGAGGTGTGAGGTGGTGATG-3' \\
\hline & Lower primer & 5'-GGAGGTTGGGCAATGGTAGAGTAG-3' \\
\hline \multirow[t]{2}{*}{ MDR1 } & Upper primer & 5'-TGGGAAGAGCACAACAGTCCAG-3 \\
\hline & Lower primer & 5'-CGTGGTGGCAAACAATACAGGTTC-3' \\
\hline \multirow[t]{2}{*}{ Nanog } & Upper primer & 5'-CCAGTCCCAAAGGCAAACAAC-3' \\
\hline & Lower primer & 5'-TGGAGGCTGAGGTATTTCTGTCTC-3' \\
\hline \multirow[t]{2}{*}{ NKX3.1 } & Upper primer & 5'-AAAGGCACTTGGGGTCTTATCTG-3' \\
\hline & Lower primer & 5'-CTTCTGATGGCTGAACTTCCTCTC-3' \\
\hline \multirow[t]{2}{*}{ NSE } & Upper primer & 5'-GTCCCACGTGTCTTCCACTT-3' \\
\hline & Lower primer & 5'-CCCAAGTCAGGCCAGTTTTA-3' \\
\hline \multirow[t]{2}{*}{ Slug } & Upper primer & 5'-GAGCATTTGCAGACAGGTCA-3' \\
\hline & Lower primer & 5'-GCTTCGGAGTGAAGAAATGC-3' \\
\hline \multirow[t]{2}{*}{ Snail } & Upper primer & 5'-ACCCCACATCCTTCTCACTG-3' \\
\hline & Lower primer & 5'-TACAAAAACCCACGCAGACA-3' \\
\hline \multirow[t]{2}{*}{$\mathrm{SOX} 2$} & Upper primer & 5'-GCACCGCTACGACGTGA-3' \\
\hline & Lower primer & 5'-TGCGAGTAGGACATGCTGTAGG-3' \\
\hline \multirow[t]{2}{*}{ sPLA2-IIa } & Upper primer & 5'-TTGACGACAGGAAAGGAAGCCG-3' \\
\hline & Lower primer & 5'-TCTGCTCCCCGAGTTGCTAAAC-3' \\
\hline \multirow[t]{2}{*}{ Twist } & Upper primer & 5'-GGAGTCCGCAGTCTTACGAG-3' \\
\hline & Lower primer & 5'-CCAGCTTGAGGGTCTGAATC-3' \\
\hline \multirow[t]{2}{*}{ Vimentin } & Upper primer & 5'-AATCCAAGTTTGCTGACCTCTCTG-3' \\
\hline & Lower primer & 5'-CTCTTCCATTTCACGCATCTGG-3' \\
\hline
\end{tabular}

NKX3.1, NSE, Slug, Snail, Sox2, and Twist $(2,3,47)$, are heterogeneously overexpressed in SP CSCs relative to non-SP control cells or in ALDH1-high CSCs relative to ALDH1-low control cells. In addition, HER2, HER3, or AR gene is also moderately increased in these CSCs. Interestingly, sPLA2-IIa levels in SP and ALDH1-high CSCs are elevated 41-fold
(H1975), 4.3-fold (A549), and 6-fold (22Rv1), respectively, suggesting that SPLA2-IIa is a novel CSC marker and supports CSC properties (Table II).

Characterization of CSCs in $3 D$ cell culture and in mice. We performed $3 \mathrm{D}$ cell culture to validate CSCs properties and 
Table II. CSCs express a high level of SPLA2-IIa.

\begin{tabular}{lccc}
\hline H1975 cells & None-SP control & SP CSCs & Fold increase \\
\hline ABCG2 & $2.26 \mathrm{E}-04$ & $3.05 \mathrm{E}-03$ & 13.53 \\
ALDH1 & $2.01 \mathrm{E}-06$ & $4.00 \mathrm{E}-05$ & 19.92 \\
CD133 & $1.01 \mathrm{E}-06$ & $4.53 \mathrm{E}-02$ & 45033.82 \\
Focx2 & $4.95 \mathrm{E}-05$ & $2.46 \mathrm{E}-04$ & 4.97 \\
HER3 & $1.20 \mathrm{E}-04$ & $5.07 \mathrm{E}-04$ & 4.21 \\
MDR1 & $3.43 \mathrm{E}-07$ & $7.19-05$ & 209.32 \\
Nanog & $4.59 \mathrm{E}-05$ & $7.80 \mathrm{E}-05$ & 1.7 \\
NKX3.1 & $4.31 \mathrm{E}-03$ & $2.83 \mathrm{E}-02$ & 6.57 \\
Slug & $1.26 \mathrm{E}-02$ & $6.91 \mathrm{E}-02$ & 5.5 \\
Snail & $5.60 \mathrm{E}-02$ & $1.83 \mathrm{E}-01$ & 3.27 \\
sPLA2-IIa & $7.66 \mathrm{E}-08$ & $3.15 \mathrm{E}-06$ & 41.1 \\
Twist & $7.66 \mathrm{E}-08$ & $3.33 \mathrm{E}-05$ & 435.24 \\
A549 cells & & & \\
SOX2 & $5.05 \mathrm{E}-04$ & $2.22 \mathrm{E}-03$ & 4.39 \\
sPLA2-IIa & $1.83 \mathrm{E}-04$ & $7.91 \mathrm{E}-04$ & 4.31 \\
Twist & $3.64 \mathrm{E}-04$ & $1.15 \mathrm{E}-03$ & 3.16 \\
\hline
\end{tabular}

\begin{tabular}{ccc}
\hline 22RV1 cells & $\begin{array}{c}\text { ALDH1-low } \\
\text { control }\end{array}$ & $\begin{array}{c}\text { ALDH1-high Fold increase } \\
\text { CSCs }\end{array}$
\end{tabular}

\begin{tabular}{lccc}
\hline ALDH1 & $2.80 \mathrm{E}-04$ & $1.81 \mathrm{E}-02$ & 64.63 \\
AR & $3.72 \mathrm{E}-05$ & $9.44 \mathrm{E}-05$ & 2.54 \\
CD133 & $1.26 \mathrm{E}-07$ & $3.56 \mathrm{E}-05$ & 283.24 \\
CD44 & $3.40 \mathrm{E}-03$ & $3.11 \mathrm{E}-02$ & 9.16 \\
CD56 & $5.99 \mathrm{E}-06$ & $2.33 \mathrm{E}-05$ & 3.89 \\
Focx2 & $5.17 \mathrm{E}-05$ & $1.79 \mathrm{E}-04$ & 3.47 \\
HER2 & $1.01 \mathrm{E}-02$ & $1.87 \mathrm{E}-02$ & 1.85 \\
HER3 & $1.08 \mathrm{E}-02$ & $2.95 \mathrm{E}-02$ & 1.56 \\
Nanog & $4.77 \mathrm{E}-04$ & $7.85 \mathrm{E}-04$ & 1.6 \\
NSE & $1.24 \mathrm{E}-02$ & $8.63 \mathrm{E}-02$ & 6.44 \\
Slug & $3.31 \mathrm{E}-06$ & $1.09 \mathrm{E}-05$ & 2.25 \\
Snail & $2.19 \mathrm{E}-04$ & $2.23 \mathrm{E}-03$ & 10.2 \\
SOX2 & $1.93 \mathrm{E}-05$ & $6.20 \mathrm{E}-05$ & 3.21 \\
sPLA2-IIa & $3.93 \mathrm{E}-06$ & $2.34 \mathrm{E}-05$ & 5.95 \\
\hline
\end{tabular}

The mRNA expression levels are determined relative to that of $\beta$-actin.

found that SP CSCs from A549 cells generate more and much larger spheroids than those by non-SP control cells (Fig. 4). Similar observation was also made in ALDH1-high CSCs from 22RV1 cells and SP CSCs from H1975 cells (data not shown).

To further characterize the tumor initiating properties of CSCs in mice, a subcutaneous inoculation of 1,000 cells/mouse of SP CSCs, but not non-SP control cells, into nude mice produced visible tumors on day 20 . The tumors reached $\sim 100 \mathrm{~mm}^{3}$ on day 30. A subcutaneous inoculation of 1,000 cells/mouse of ALDH1-high CSCs, but not ALDH1-low

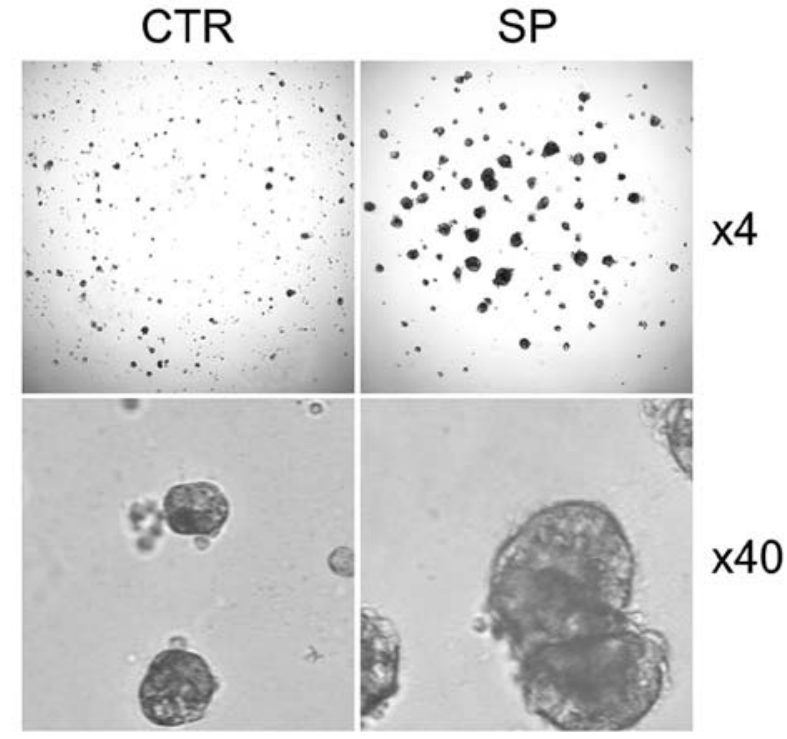

Figure 4. 3D culture of A549 cells. A 96-well plate was coated with $100 \mu \mathrm{l} /$ well of medium containing $0.9 \%$ agarose. SP CSCs and non-SP control cells in medium with $10 \%$ FBS on ice were mixed with the same volume of cold $\left(4^{\circ} \mathrm{C}\right)$ medium containing $10 \%$ FBS and $10 \%$ growth factor-reduced Matrigel matrix and seeded into the 3D culture plate at $100 \mu 1 /$ well. The cells were cultured at $37^{\circ} \mathrm{C}$ for 14 days.

Table III. Establishment of taxane-resistant 22Rv1-R cell line.

\begin{tabular}{lrrr}
\hline Gene & pTx & dTx & cTx \\
\hline 22Rv1 & 2 & 1 & 1 \\
22Rv1-R & 327 & 305 & 15 \\
R index & 164 & 305 & 15 \\
\hline
\end{tabular}

$\mathrm{IC}_{50}(\mathrm{nM})$ of the cells to pTx, dTx, and cTx in a 4-day MTT assay. Resistance $(\mathrm{R})$ index $=\mathrm{IC}_{50}$ of $22 \mathrm{Rv} 1-\mathrm{R} / \mathrm{IC}_{50}$ of $22 \mathrm{Rv} 1$.

control cells, into nude mice produced tumors on day 25 . The tumors reached $\sim 100 \mathrm{~mm}^{3}$ on day 35 .

Overexpression of CSC markers in CRPC LNCAP-AI cells and taxane-resistant 22Rvl-R cells. CRPC LNCaP-AI cells were established by culturing androgen-dependent LNCaP cells in the stripped medium as we described previously (36). CRPC 22Rv1 cells express constitutively active androgen receptor $(48,49)$. We cultured 22Rv1 cells in the presence of increasing concentrations of paclitaxel to derive 22Rv1-R cells. As shown in Table III, 22Rv1-R cells are resistant to all taxenes.

We found that CSC markers, including ABCG2, ALDH1, CD44, CD56, Focx2, MDR1, Nanog, NSE, Snail, Sox2, and Vimentin, were heterogeneously overexpressed in LNCaP-AI cells relative to parental LNCaP cells (Table IV) and in taxane-resistant 22Rv1-R cells relative to parental 22Rv1 cells (Table V). Strikingly, MDR1 level is increased by 1,380-fold in 22Rv1-R cells and 66-fold in LNCaP-AI cells. The expression of sPLA2-IIa in LNCaP-AI cells relative to LNCaP cells is increased 60-fold (Table IV), confirming the finding reported 
Table IV. Overexpression of CSC markers in CRPC LNCaP-AI cells.

\begin{tabular}{lccc}
\hline Gene & LNCaP cells & LNCaP-AI cells & Fold increase \\
\hline ALDH1 & $5.60 \mathrm{E}-05$ & $2.77 \mathrm{E}-04$ & 4.94 \\
CD44 & $8.96 \mathrm{E}-05$ & $1.19 \mathrm{E}-04$ & 2.44 \\
CD56 & $1.20 \mathrm{E}-06$ & $8.10 \mathrm{E}-05$ & 67.74 \\
MDR1 & $4.49 \mathrm{E}-06$ & $2.97 \mathrm{E}-04$ & 66.2 \\
Nanog & $2.95 \mathrm{E}-04$ & $5.54 \mathrm{E}-04$ & 1.88 \\
NSE & $2.64 \mathrm{E}-03$ & $8.11 \mathrm{E}-03$ & 3.07 \\
SOX2 & $2.40 \mathrm{E}-07$ & $1.26 \mathrm{E}-06$ & 8 \\
sPLA2-IIa & $9.19 \mathrm{E}-03$ & $5.50 \mathrm{E}-01$ & 59.9 \\
Vimentin & $2.35 \mathrm{E}-03$ & $8.55 \mathrm{E}-02$ & 36.4 \\
\hline
\end{tabular}

The mRNA expression levels are determined relative to that of $\beta$-actin.

Table V. Overexpression of CSC markers in taxane-resistant CRPC 22RV1-R cells.

\begin{tabular}{lccc}
\hline Gene & 22RV1 cells & 22RV1-R cells & Fold increase \\
\hline ABCG2 & $1.98 \mathrm{E}-03$ & $1.17 \mathrm{E}-02$ & 5.89 \\
ALDH1 & $1.35 \mathrm{E}-03$ & $5.63 \mathrm{E}-03$ & 4.18 \\
CD44 & $2.30 \mathrm{E}-03$ & $6.56 \mathrm{E}-03$ & 2.85 \\
Focx2 & $6.70 \mathrm{E}-06$ & $3.29 \mathrm{E}-05$ & 4.91 \\
MDR1 & $1.56 \mathrm{E}-04$ & $2.15 \mathrm{E}-01$ & $1,380.42$ \\
Nanog & $3.02 \mathrm{E}-04$ & $1.03 \mathrm{E}-03$ & 3.4 \\
NSE & $3.19 \mathrm{E}-02$ & $9.42 \mathrm{E}-02$ & 3 \\
Snail & $5.56 \mathrm{E}-04$ & $3.80 \mathrm{E}-03$ & 9.9 \\
SOX2 & $1.04 \mathrm{E}-04$ & $2.52 \mathrm{E}-04$ & 2.57 \\
\hline
\end{tabular}

The mRNA expression levels are determined relative to that of $\beta$-actin.

in our previous study (13). sPLA2-IIa is not overexpressed in $22 \mathrm{Rv} 1-\mathrm{R}$ cells relative to $22 \mathrm{Rv} 1$ cells, but is overexpressed in CSCs from 22Rv1 cells (Table II), indicating the heterogeneity of gene expression in cancer cells. These findings suggest that CSC population is elevated in LNCaP-AI and 22Rv1-R cells, supporting the notion that the current anticancer therapies favor the selection and expansion of CSCs.

\section{Discussion}

We demonstrated that cancer cells overexpress and secrete sPLA2-IIa into the interstitial fluid, i.e., tumor microenvironment and blood $(13,29,30)$. Plasma sPLA2-IIa continuously increased with prostate cancer progression and reached as high as $18 \mathrm{ng} / \mathrm{ml}$ at the late stage in metastatic prostate cancer (29). High levels of plasma sPLA2-IIa, based on the optimum cutoff value of $2.0 \mathrm{ng} / \mathrm{ml}$, significantly predicted advanced stage and high Gleason score in prostate cancer $(13,29)$. We further showed that sPLA2-IIa is overexpressed in almost all lung cancers and is significantly elevated in the blood of lung cancer patients (30). High levels of plasma sPLA2-IIa, at the optimum cutoff value of $2.4 \mathrm{ng} / \mathrm{ml}$, are significantly associated with advanced lung cancer stage and decreased overall cancer survival (30). The most recent report by others supports our finding in that high levels of plasma sPLA2-IIa are associated with poor prognosis of cancers (31).

The ultimate cause of cancer treatment failure is that tumor cells evolve and develop multiple mechanisms to escape the cytotoxic effects of anticancer drugs, including enhancement of cell survival pathway, impaired apoptotic machinery, increased DNA repair mechanisms, and multidrug resistance phenotype by overexpression of drug-efflux pump proteins P-glycoprotein (MDR1) and ABCG-2 (50-52). These mechanisms may also drive CSC properties and tumor progression. ATP-binding cassette (ABC) transporters, such as P-glycoprotein (MDR1), multidrug resistant associated protein (MRP1), and ATP-binding cassette membrane transporter G2 [ABCG2, also known as breast cancer resistance protein 1 (BCRP1)], are membrane transporters that can pump cytotoxic chemotherapeutic drugs out of the cell. CSCs express high levels of $\mathrm{ABC}$ transporters leading to low intracellular drug concentrations and conferring multidrug resistance to many anticancer drugs. The efflux capacity of SP CSCs, determined by high ABCG2 activity, is associated with tumor growth, progression, and metastasis. The aldehyde dehydrogenase (ALDH) family members are cytosolic isoenzymes responsible for oxidizing intracellular aldehydes. ALDH1-high CSCs are highly resistant to chemotherapeutic agents commonly used as first-line therapy in the clinical setting, such as cisplatin, gemcitabine, doxorubicin, vinorelbine and docetaxel, whereas ALDH1-low cells are sensitive to the cytotoxic activity of these drugs. In the present study, we found that both SP CSCs from NSCLC cells and ALDH1-high CSCs from CRPC cells overexpress a number of CSC markers, supporting the notion that multiple mechanisms contribute to CSC phenotype (Table II). More importantly, we found that both SP CSCs and ALDH1-high CSCs overexpress sPLA2-IIa. It was reported that ALDH1-high CSCs from lung cancer cells also overexpress sPLA2-IIa (53). These findings strongly suggest that sPLA2-IIa is a marker for CSCs and may support CSC properties.

Gene amplification, overexpression, and mutations in EGFR family receptors have been well described in various cancers, including breast, head and neck, prostate, and NSCLC, and contribute to resistance to therapy and cancer progression (54-59). EGF is a preferable ligand for EGFR/EGFR homodimer or EGFR/HER2 heterodimer, while heregulin-a is a preferable ligand for HER2/HER3 heterodimer $(34,60,61)$. HER 2 has no ligand and HER3 has no tyrosine kinase activity, and they function by forming heterodimer with other HER receptor. Because HER3 has six tyrosine containing binding sites for $\mathrm{p} 85$, the regulatory subunit of PI3K, HER2/HER3 complex is much more effective than EGFR/HER2 in activation of the PI3K/Akt pathway. HER3, which signaling function cannot be inhibited by tyrosine kinase inhibitor (TKI), provides a focal point in resistance to TKI therapy (62). Increasing body of evidence highlight the role of HER3 in lung cancer, which has not been successfully addressed in the targeted therapy to date. By coupling to numerous signaling pathways, such as 
the RAS-ERK and PI3K-Akt pathways, and multiple feedback regulatory loops, HER/ERBB-elicited signaling propels the clonal expansion of CSCs (33-35). One such positive feedback loop is stimulation of sPLA2-IIa overexpression via HER/ ERBB-PI3K-Akt-NF- $\kappa B$ signaling $(13,29,30)$. We uncovered that elevated HER/ERBB-PI3K-Akt-NF- $\mathrm{KB}$ signaling induces sPLA2-IIa overexpression and secretion in both lung and prostate cancer cells, and in turn, sPLA2-IIa activates EGFR family receptors and HER/ERBB-elicited signaling and stimulates sPLA2-IIa overexpression in a positive feedback manner $(13,29,30)$.

We further investigated the molecular action of sPLA2-IIa. Given the potential ligand activity of sPLA2-IIa, we hypothesized that SPLA2-IIa functions as a ligand for EGFR family receptors, leading to an enhanced HER/ERBB-elicited signaling. Indeed, we found that sPLA2-IIa enhances HER/ERBB-PI3K-Akt-NF- $\kappa B$ signaling in both prostate cancer cells (Figs. 1 and 2) and lung cancer cells (32). Our protein docking analysis and co-immunoprecipitation experiments revealed that sPLA2-IIa interacts with EGFR family receptors (Fig. 2) (32). sPLA2-IIa directly or indirectly interacts with EGFR, HER2, and HER3, suggesting that it may be a ligand for both EGFR and HER3. Given that both SP and ALDH1-high CSCs overexpress sPLA2-IIa (Table II), sPLA2-IIa in the tumor microenvironment may function as a ligand for EGFR family receptors, stimulates HER/ERBBelicited signaling, and promotes the clonal expansion of CSCs and cancer progression (33-35).

SPLA2-IIa stimulates growth of prostate cancer cells $(13,27,63)$, colon cancer cells $(64)$, and brain tumor cells $(65,66)$, which may be via the EGFR-, MAPK-, PI3K/ Akt-, NF- $\mathrm{KB}$-mediated cell growth and survival signaling pathways (67-70). sPLA2-IIa abrogates TNF- $\alpha$-induced apoptosis and compromises immune surveillance function (71). In the transgenic adenocarcinoma of the mouse prostate (TRAMP) model, sPLA2-IIa contributes to aggressive phenotypes, androgen-independent growth, and metastasis (72). sPLA2-IIa binds to integrins and induces proliferation of monocytic cells in an integrin-dependent manner (16). We showed that sPLA2-IIa is overexpressed in CSCs, which may support CSC properties. On the other hand, knocking down expression of sPLA2-IIa reduces lung cancer growth (73). Our previous and current studies revealed the underlying mechanisms of sPLA2-IIa action, in which sPLA2-IIa functions as a ligand for EGFR family receptors, leading to sPLA2-IIa overexpression via HER/ERBB-PI3K-Akt-NF- $\kappa B$ signaling in a positive feedback manner. Aberrant high levels of sPLA2-IIa in the tumor microenvironment support CSC properties and contribute to cancer progression and metastasis. SPLA2-IIa is a novel therapeutic target against cancer.

It has been shown that the treatment with taxol and cisplatin may not affect growth, but can even stimulate growth in CSCs $(74,75)$. Similarly, castration has been shown to induce epithelial-mesenchymal transition, promote growth of CSCs in prostate cancer, and lead to castration-resistance and metastasis (10). Consistent with these observations, we found that CRPC LNCaP-AI cells, selected in the stripped medium (36), and multidrug resistant 22Rv1-R cells, derived from CRPC 22Rv1 cells selected in the medium containing paclitaxel, overexpress several CSC markers and drug efflux pump proteins (Tables IV and V). Therefore, LNCaP-AI and 22Rv1-R cells provide valuable tools for studying CSCs and determine the roles of sPLA2-IIa in tumor progression.

\section{Acknowledgements}

This study was supported in part by the Millennium Scholar funds of University of Cincinnati Cancer Center and a pilot grant from the Department of Internal Medicine, University of Cincinnati College of Medicine.

\section{References}

1. O'Flaherty JD, Barr M, Fennell D, Richard D, Reynolds J, O'Leary J and O'Byrne K: The cancer stem-cell hypothesis: Its emerging role in lung cancer biology and its relevance for future therapy. J Thorac Oncol 7: 1880-1890, 2012.

2. Leon G, MacDonagh L, Finn SP, Cuffe S and Barr MP: Cancer stem cells in drug resistant lung cancer: Targeting cell surface markers and signaling pathways. Pharmacol Ther 158: 71-90, 2016.

3. MacDonagh L, Gray SG, Breen E, Cuffe S, Finn SP, O'Byrne KJ and Barr MP: Lung cancer stem cells: The root of resistance. Cancer Lett 372: 147-156, 2016.

4. Liu T, Xu F, Du X, Lai D, Liu T, Zhao Y, Huang Q, Jiang L, Huang W, Cheng W, et al: Establishment and characterization of multidrug resistant, prostate carcinoma-initiating stem-like cells from human prostate cancer cell lines 22RV1. Mol Cell Biochem 340: 265-273, 2010.

5. Fang DD, Cao J, Jani JP, Tsaparikos K, Blasina A, Kornmann J, Lira ME, Wang J, Jirout Z, Bingham J, et al: Combined gemcitabine and CHK1 inhibitor treatment induces apoptosis resistance in cancer stem cell-like cells enriched with tumor spheroids from a non-small cell lung cancer cell line. Front Med 7: 462-476, 2013.

6. Vlashi E and Pajonk F: The metabolic state of cancer stem cells - a valid target for cancer therapy? Free Radic Biol Med 79: 264-268, 2015.

7. Pfeiffer MJ and Schalken JA: Stem cell characteristics in prostate cancer cell lines. Eur Urol 57: 246-254, 2010.

8. Lagadec C, Vlashi E, Della Donna L, Dekmezian C and Pajonk F: Radiation-induced reprogramming of breast cancer cells. Stem Cells 30: 833-844, 2012

9. Ghisolfi L, Keates AC, Hu X, Lee DK and Li CJ: Ionizing radiation induces stemness in cancer cells. PLoS One 7: e43628, 2012.

10. Li P, Yang R and Gao WQ: Contributions of epithelial-mesenchymal transition and cancer stem cells to the development of castration resistance of prostate cancer. Mol Cancer 13: 55, 2014.

11. Brown MD, Gilmore PE, Hart CA, Samuel JD, Ramani VA, George NJ and Clarke NW: Characterization of benign and malignant prostate epithelial Hoechst 33342 side populations. Prostate 67: 1384-1396, 2007.

12. Antonio V, Brouillet A, Janvier B, Monne C, Bereziat G, Andreani $M$ and Raymondjean $M$ : Transcriptional regulation of the rat type IIA phospholipase A2 gene by cAMP and interleukin-1beta in vascular smooth muscle cells: Interplay of the CCAAT/enhancer binding protein (C/EBP), nuclear factor-kappaB and Ets transcription factors. Biochem J 368: 415-424, 2002.

13. Dong Z, Liu Y, Scott KF, Levin L, Gaitonde K, Bracken RB, Burke B, Zhai QJ, Wang J, Oleksowicz L, et al: Secretory phospholipase A2-IIa is involved in prostate cancer progression and may potentially serve as a biomarker for prostate cancer. Carcinogenesis 31: 1948-1955, 2010.

14. Cummings BS: Phospholipase A2 as targets for anti-cancer drugs. Biochem Pharmacol 74: 949-959, 2007.

15. Triggiani M, Granata F, Giannattasio G and Marone G: Secretory phospholipases A2 in inflammatory and allergic diseases: Not just enzymes. J Allergy Clin Immunol 116: 1000-1006, 2005.

16. Saegusa J, Akakura N, Wu CY, Hoogland C, Ma Z, Lam KS, Liu FT, Takada YK and Takada Y: Pro-inflammatory secretory phospholipase A2 type IIA binds to integrins alphavbeta3 and alpha4beta1 and induces proliferation of monocytic cells in an integrin-dependent manner. J Biol Chem 283: 26107-26115, 2008. 
17. Triggiani M, Granata F, Balestrieri B, Petraroli A, Scalia G Del Vecchio L and Marone G: Secretory phospholipases A2 activate selective functions in human eosinophils. J Immunol 170: 3279-3288, 2003

18. Tada K, Murakami M, Kambe T and Kudo I: Induction of cyclooxygenase- 2 by secretory phospholipases A2 in nerve growth factor-stimulated rat serosal mast cells is facilitated by interaction with fibroblasts and mediated by a mechanism independent of their enzymatic functions. J Immunol 161: 5008-5015, 1998

19. Cupillard L, Mulherkar R, Gomez N, Kadam S, Valentin E, Lazdunski $M$ and Lambeau $G$ : Both group IB and group IIA secreted phospholipases A2 are natural ligands of the mouse 180-kDa M-type receptor. J Biol Chem 274: 7043-7051, 1999.

20. Nicolas JP, Lambeau G and Lazdunski M: Identification of the binding domain for secretory phospholipases A2 on their M-type 180-kDa membrane receptor. J Biol Chem 270: 28869-28873, 1995.

21. Scott KF, Sajinovic M, Hein J, Nixdorf S, Galettis P, Liauw W, de Souza P, Dong Q, Graham GG and Russell PJ: Emerging roles for phospholipase A2 enzymes in cancer. Biochimie 92: 601-610, 2010.

22. Meyer AM, Dwyer-Nield LD, Hurteau GJ, Keith RL, O'Leary E, You M, Bonventre JV, Nemenoff RA and Malkinson AM: Decreased lung tumorigenesis in mice genetically deficient in cytosolic phospholipase A2. Carcinogenesis 25: 1517-1524, 2004

23. Kallajoki M, Alanen KA, Nevalainen M and Nevalainen TJ Group II phospholipase A2 in human male reproductive organs and genital tumors. Prostate 35: 263-272, 1998 .

24. Jiang J, Neubauer BL, Graff JR, Chedid M, Thomas JE, Roehm NW, Zhang S, Eckert GJ, Koch MO, Eble JN, et al: Expression of group IIA secretory phospholipase A2 is elevated in prostatic intraepithelial neoplasia and adenocarcinoma. Am J Pathol 160: 667-671, 2002.

25. Graff JR, Konicek BW, Deddens JA, Chedid M, Hurst BM, Colligan B, Neubauer BL, Carter HW and Carter JH: Expression of group IIa secretory phospholipase A 2 increases with prostate tumor grade. Clin Cancer Res 7: 3857-3861, 2001.

26. Dong Z, Liu Y, Levin L, Oleksowicz L, Wang J and Lu S: Vav3 oncogene is involved in regulation of secretory phospholipase A2-IIa expression in prostate cancer. Oncol Rep 25: 1511-1516, 2011.

27. Sved P, Scott KF, McLeod D, King NJ, Singh J, Tsatralis T, Nikolov B, Boulas J, Nallan L, Gelb MH, et al: Oncogenic action of secreted phospholipase A2 in prostate cancer. Cancer Res 64 6934-6940, 2004

28. Mirtti T, Laine VJ, Hiekkanen H, Hurme S, Rowe O, Nevalainen TJ, Kallajoki M and Alanen K: Group IIA phospholipase A as a prognostic marker in prostate cancer: Relevance to clinicopathological variables and disease-specific mortality. APMIS 117: 151-161, 2009.

29. Oleksowicz L, Liu Y, Bracken RB, Gaitonde K, Burke B, Succop P Levin L, Dong Z and Lu S: Secretory phospholipase A2-IIa is a target gene of the HER/HER2-elicited pathway and a potential plasma biomarker for poor prognosis of prostate cancer. Prostate 72: 1140-1149, 2012

30. Kupert E, Anderson M, Liu Y, Succop P, Levin L, Wang J, Wikenheiser-brokamp K, Chen P, Pinney SM, Macdonald T, et al: Plasma secretory phospholipase A2-IIa as a potential biomarker for lung cancer in patients with solitary pulmonary nodules. BMC Cancer 11: 513, 2011.

31. Menschikowski M, Hagelgans A, Schuler U, Froeschke S, Rosner A and Siegert G: Plasma levels of phospholipase A2-IIA in patients with different types of malignancies: Prognosis and association with inflammatory and coagulation biomarkers Pathol Oncol Res 19: 839-846, 2013.

32. Dong Z, Meller J, Succop P, Wang J, Wikenheiser-Brokamp K, Starnes S and Lu S: Secretory phospholipase A2-IIa upregulates HER/HER2-elicited signaling in lung cancer cells. Int J Oncol 45: 978-984, 2014

33. Mimeault M, Hauke R, Mehta PP and Batra SK: Recent advances in cancer stem/progenitor cell research: Therapeutic implications for overcoming resistance to the most aggressive cancers. J Cell Mol Med 11: 981-1011, 2007.

34. Schneider MR and Yarden Y: The EGFR-HER2 module: A stem cell approach to understanding a prime target and driver of solid tumors. Oncogene 35: 2949-2960, 2016.

35. Singh S, Trevino J, Bora-Singhal N, Coppola D, Haura E, Altiok S and Chellappan SP: EGFR/Src/Akt signaling modulates Sox 2 expression and self-renewal of stem-like side-population cells in non-small cell lung cancer. Mol Cancer 11: 73, 2012.

36. Lu S, Tsai SY and Tsai MJ: Molecular mechanisms of androgenindependent growth of human prostate cancer LNCaP-AI cells Endocrinology 140: 5054-5059, 1999.
37. Ho MM, Ng AV, Lam S and Hung JY: Side population in human lung cancer cell lines and tumors is enriched with stem-like cancer cells. Cancer Res 67: 4827-4833, 2007.

38. Li T, Su Y, Mei Y, Leng Q, Leng B, Liu Z, Stass SA and Jiang F: ALDH1A1 is a marker for malignant prostate stem cells and predictor of prostate cancer patients' outcome. Lab Invest 90: 234-244, 2010.

39. Doherty RE, Haywood-Small SL, Sisley K and Cross NA: Aldehyde dehydrogenase activity selects for the holoclone phenotype in prostate cancer cells. Biochem Biophys Res Commun 414: 801-807, 2011.

40. Marcato P, Dean CA, Giacomantonio CA and Lee PW: Aldehyde dehydrogenase: Its role as a cancer stem cell marker comes down to the specific isoform. Cell Cycle 10: 1378-1384, 2011.

41. Januchowski R, Wojtowicz K and Zabel M: The role of aldehyde dehydrogenase (ALDH) in cancer drug resistance. Biomed Pharmacother 67: 669-680, 2013.

42. Singh S, Brocker C, Koppaka V, Chen Y, Jackson BC, Matsumoto A, Thompson DC and Vasiliou V: Aldehyde dehydrogenases in cellular responses to oxidative/electrophilic stress. Free Radic Biol Med 56: 89-101, 2013.

43. Wu A, Luo W, Zhang Q, Yang Z, Zhang G, Li S and Yao K: Aldehyde dehydrogenase 1, a functional marker for identifying cancer stem cells in human nasopharyngeal carcinoma. Cancer Lett 330: 181-189, 2013.

44. Nishida S, Hirohashi Y, Torigoe T, Kitamura H, Takahashi A, Masumori N, Tsukamoto T and Sato N: Gene expression profiles of prostate cancer stem cells isolated by aldehyde dehydrogenase activity assay. J Urol 188: 294-299, 2012.

45. Nishida S, Hirohashi Y, Torigoe T, Inoue R, Kitamura H, Tanaka T, Takahashi A, Asanuma H, Masumori N, Tsukamoto T, et al: Prostate cancer stem-like cells/cancer-initiating cells have an autocrine system of hepatocyte growth factor. Cancer Sci 104 431-436, 2013

46. Jiang F, Qiu Q, Khanna A, Todd NW, Deepak J, Xing L, Wang H, Liu Z, Su Y, Stass SA, et al: Aldehyde dehydrogenase 1 is a tumor stem cell-associated marker in lung cancer. Mol Cancer Res 7: 330-338, 2009.

47. Mimeault M and Batra SK: Recent progress on tissue-resident adult stem cell biology and their therapeutic implications. Stem Cell Rev 4: 27-49, 2008

48. Hu R, Dunn TA, Wei S, Isharwal S, Veltri RW, Humphreys E, Han M, Partin AW, Vessella RL, Isaacs WB, et al: Ligandindependent androgen receptor variants derived from splicing of cryptic exons signify hormone-refractory prostate cancer. Cancer Res 69: 16-22, 2009.

49. Dehm SM, Schmidt LJ, Heemers HV, Vessella RL and Tindall DJ: Splicing of a novel androgen receptor exon generates a constitutively active androgen receptor that mediates prostate cancer therapy resistance. Cancer Res 68: 5469-5477, 2008.

50. Munoz M, Henderson M, Haber M and Norris M: Role of the MRP1/ABCC1 multidrug transporter protein in cancer. IUBMB Life 59: 752-757, 2007.

51. Modok S, Mellor HR and Callaghan R: Modulation of multidrug resistance efflux pump activity to overcome chemoresistance in cancer. Curr Opin Pharmacol 6: 350-354, 2006.

52. Signore M, Ricci-Vitiani L and De Maria R: Targeting apoptosis pathways in cancer stem cells. Cancer Lett 332: 374-382, 2013.

53. Bennett DT, Deng XS, Yu JA, Bell MT, Mauchley DC, Meng X, Reece TB, Fullerton DA and Weyant MJ: Cancer stem cell phenotype is supported by secretory phospholipase A2 in human lung cancer cells. Ann Thorac Surg 98: 439-445; discussion 445-436, 2014.

54. Di Lorenzo G, Tortora G, D'Armiento FP, De Rosa G, Staibano S, Autorino R, D'Armiento M, De Laurentiis M, De Placido S, Catalano G, et al: Expression of epidermal growth factor receptor correlates with disease relapse and progression to androgenindependence in human prostate cancer. Clin Cancer Res 8: 3438-3444, 2002.

55. Shi Y, Brands FH, Chatterjee S, Feng AC, Groshen S, Schewe J, Lieskovsky $\mathrm{G}$ and Cote RJ: Her-2/neu expression in prostate cancer: High level of expression associated with exposure to hormone therapy and androgen independent disease. J Urol 166: 1514-1519, 2001.

56. Osman I, Scher HI, Drobnjak M, Verbel D, Morris M, Agus D, Ross JS and Cordon-Cardo C: HER-2/neu (p185neu) protein expression in the natural or treated history of prostate cancer. Clin Cancer Res 7: 2643-2647, 2001.

57. Signoretti S, Montironi R, Manola J, Altimari A, Tam C, Bubley G, Balk S, Thomas G, Kaplan I, Hlatky L, et al: Her-2-neu expression and progression toward androgen independence in human prostate cancer. J Natl Cancer Inst 92: 1918-1925, 2000 
58. Yeh S, Lin HK, Kang HY, Thin TH, Lin MF and Chang C: From HER2/Neu signal cascade to androgen receptor and its coactivators: A novel pathway by induction of androgen target genes through MAP kinase in prostate cancer cells. Proc Natl Acad Sci USA 96: 5458-5463, 1999.

59. Craft N, Shostak Y, Carey M and Sawyers CL: A mechanism for hormone-independent prostate cancer through modulation of androgen receptor signaling by the HER-2/neu tyrosine kinase. Nat Med 5: 280-285, 1999.

60. Schulze WX, Deng L and Mann M: Phosphotyrosine interactome of the ErbB-receptor kinase family. Mol Syst Biol 1: 2005 0008, 2005.

61. Hsieh AC and Moasser MM: Targeting HER proteins in cancer therapy and the role of the non-target HER3. Br J Cancer 97 453-457, 2007.

62. Tsao MS, Sakurada A, Cutz JC, Zhu CQ, Kamel-Reid S, Squire J, Lorimer I, Zhang T, Liu N, Daneshmand M, et al: Erlotinib in lung cancer - molecular and clinical predictors of outcome. N Engl J Med 353: 133-144, 2005.

63. Patel MI, Singh J, Niknami M, Kurek C, Yao M, Lu S, Maclean F, King NJ, Gelb MH, Scott KF, et al: Cytosolic phospholipase A2-alpha: A potential therapeutic target for prostate cancer. Clin Cancer Res 14: 8070-8079, 2008.

64. Belinsky GS, Rajan TV, Saria EA, Giardina C and Rosenberg DW: Expression of secretory phospholipase A2 in colon tumor cells potentiates tumor growth. Mol Carcinog 46: 106-116, 2007.

65. Hernández M, Martín R, García-Cubillas MD, MaesoHernández P and Nieto ML: Secreted PLA2 induces proliferation in astrocytoma through the EGF receptor: Another inflammation-cancer link. Neuro-oncol 12: 1014-1023, 2010.

66. Martín R, Hernández M, Ibeas E, Fuentes L, Salicio V, Arnés M and Nieto ML: Secreted phospholipase A2-IIA modulates key regulators of proliferation on astrocytoma cells. J Neurochem 111: 988-999, 2009.

67. Valentin E and Lambeau G: Increasing molecular diversity of secreted phospholipases $\mathrm{A}(2)$ and their receptors and binding proteins. Biochim Biophys Acta 1488: 59-70, 2000.
68. Lambeau $\mathrm{G}$ and Lazdunski M: Receptors for a growing family of secreted phospholipases A2. Trends Pharmacol Sci 20: 162-170, 1999.

69. Hernández M, Burillo SL, Crespo MS and Nieto ML: Secretory phospholipase A2 activates the cascade of mitogen-activated protein kinases and cytosolic phospholipase A2 in the human astrocytoma cell line 1321N1. J Biol Chem 273: 606-612, 1998.

70. Park DW, Kim JR, Kim SY, Sonn JK, Bang OS, Kang SS, Kim JH and Baek SH: Akt as a mediator of secretory phospholipase A2 receptor-involved inducible nitric oxide synthase expression. J Immunol 170: 2093-2099, 2003.

71. Ibeas E, Fuentes L, Martín R, Hernández M and Nieto ML: Inflammatory protein sPLA(2)-IIA abrogates TNFalpha-induced apoptosis in human astroglioma cells: Crucial role of ERK. Biochim Biophys Acta 1793: 1837-1847, 2009.

72. Morgenbesser SD, McLaren RP, Richards B, Zhang M, Akmaev VR, Winter SF, Mineva ND, Kaplan-Lefko PJ, Foster BA, Cook BP, et al: Identification of genes potentially involved in the acquisition of androgen-independent and metastatic tumor growth in an autochthonous genetically engineered mouse prostate cancer model. Prostate 67: 83-106, 2007.

73. Yu JA, Mauchley D, Li H, Meng X, Nemenoff RA, Fullerton DA and Weyant MJ: Knockdown of secretory phospholipase A2 IIa reduces lung cancer growth in vitro and in vivo. $\mathrm{J}$ Thorac Cardiovasc Surg 144: 1185-1191, 2012.

74. Larzabal L, El-Nikhely N, Redrado M, Seeger W, Savai R and Calvo A: Differential effects of drugs targeting cancer stem cell (CSC) and non-CSC populations on lung primary tumors and metastasis. PLoS One 8: e79798, 2013.

75. Lopez-Ayllon BD, Moncho-Amor V, Abarrategi A, Ibañez de Cáceres I, Castro-Carpeño J, Belda-Iniesta C, Perona R and Sastre L: Cancer stem cells and cisplatin-resistant cells isolated from non-small-lung cancer cell lines constitute related cell populations. Cancer Med 3: 1099-1111, 2014. 